\title{
Preventive Effect of Long-term Aldose Reductase Inhibition (Ponalrestat) on Nerve Conduction and Sural Nerve Structure in the Spontaneously Diabetic Bio-Breeding Rat
}

\author{
Anders A. F. Sima, Ashok Prashar, Wei-Xian Zhang, Subrata Chakrabarti, and Douglas A. Greene* \\ Neuropathology Research Laboratory, Department of Pathology, University of Manitoba, Winnipeg, Manitoba, \\ R3E 0W3, Canada; and *Diabetes Research and Training Center and Department of Internal Medicine, \\ University of Michigan Medical Center, Ann Arbor, Michigan 48109
}

\begin{abstract}
To test the hypothesis that aldose reductase inhibition may prevent or delay the development of functional and structural neuropathy in the insulin-deficient diabetic Bio-Breeding rat (BB-rat), hyperglycemic rats were begun on the aldose reductase inhibitor (ARI) ponalrestat $25 \mathrm{mg} / \mathrm{kg}$ body wt soon after the onset of diabetes and followed for 4 or 6 mo. Ponalrestat treatment completely prevented the characteristic nerve conduction slowing and structural abnormalities of the node of Ranvier for 4 mo despite only partial preservation of axonal integrity. Ponalrestat treatment for 6 mo achieved a partial but significant prevention of nerve conduction slowing, axoglial dysjunction, and axonal degenerative changes. This incomplete but significant prevention of neuropathy by ponalrestat suggests that additional mechanisms besides polyol-pathway activation may be of importance in the pathogenesis of diabetic neuropathy. Alternatively, the dosage used in the present study may not have been sufficient to achieve a complete prevention. Despite the only partial protective effect of ARI treatment on degenerative peripheral nerve changes in hyperglycemic BBrats, 6 mo of treatment resulted in a more than threefold increase in regenerating nerve fibers. These data suggest that prophylactic ARI treatment may be efficacious in delaying the development of diabetic neuropathy. (J. Clin. Invest. 1990. 85:1410-1420.) diabetic neuropathy $\bullet$ prevention $\bullet$ polyol pathway • morphometry • electrophysiology
\end{abstract}

\section{Introduction}

The neuropathy accompanying diabetes mellitus is believed to be the result of altered nerve metabolism initiated by insulin deficiency and/or hyperglycemia and unspecified genetic and/ or environmental factors (1-4). We and others (5-10) have previously demonstrated that reversible abnormalities in nerve

This work was presented in part at the 49th Annual Meeting of the American Diabetes Association, Detroit, MI, in June 1989.

Dr. Zhang is a visiting scientist from the Medical University of Shanghai, People's Republic of China.

Address reprint requests to Dr. Sima, Neuropathology Research Laboratory, Department of Pathology, University of Manitoba, 770 Bannatyne Avenue, Winnipeg, Manitoba, Canada R3E OW3.

Received for publication 28 June 1989 and in revised form 29 December 1989.

J. Clin. Invest.

(c) The American Society for Clinical Investigation, Inc. $0021-9738 / 90 / 05 / 1410 / 11 \$ 2.00$

Volume 85, May 1990, 1410-1420 metabolism in diabetic rodents are directly associated with a reversible nerve conduction defect similar to that seen in acute human diabetes $(11,12)$. The spontaneously diabetic BioBreeding rat (BB-rat) ${ }^{1}$ demonstrates both reversible metabolic abnormalities and nerve conduction slowing, as well as subsequent morphologic lesions characteristic of diabetic neuropathy in humans $(5,13,14)$. Hence, this model provides a unique system in which to explore the effect of pharmacological correction of early metabolic abnormalities on the subsequent development of more advanced functional and structural diabetic neuropathy. The metabolic events in peripheral nerve triggered by hyperglycemia involve activation of the polyol pathway and impairments in myo-inositol (MI) metabolism and $(\mathrm{Na}, \mathrm{K})-\mathrm{ATPase}$ activity, in association with a decreased protein kinase $C$ activity $(8,15,16)$. However, in other target tissues of diabetic complication, such as retinal endothelial cells, activation of the polyol pathway by hyperglycemia does not effect MI metabolism and increases the membranous pool of protein kinase $\mathrm{C}$ activity (17).

In the BB-rat a readily reversible conduction defect after 3 wk of diabetes is the result of decreased nodal Na equilibrium potential consequent to impaired ( $\mathrm{Na}, \mathrm{K})$-ATPase activity and is accompanied by paranodal axonal swelling attributed to a fivefold increase in axonal $\mathrm{Na}$ concentration $(8,18,19)$. These acute metabolic and electrophysiological defects and early structural abnormalities are completely normalized by shortterm insulin treatment designed to achieve euglycemia, and by MI supplementation and aldose reductase inhibitor (ARI) treatment (6). Prolonged hyperglycemia in the BB-rat further slows nerve conduction via irreversibly decreased nodal $\mathrm{Na}$ permeability accompanied by disruption of axon-myelin junctional complexes at the node of Ranvier (axoglial dysjunction) $(20,21)$. Metabolic correction at this chronic stage of diabetes only partially corrects the nerve conduction defect. The remaining irreversible component of conduction slowing correlates quantitatively with axoglial dysjunction and is presumably accounted for by the associated residual defect in nodal sodium permeability $(8,20)$. Hence, extrapolation of the sequential metabolic, functional, and structural abnormalities in the diabetic BB-rat to human subjects would suggest that activation of the polyol pathway may play an initiating role in the development of clinically overt diabetic neuropathy. Indeed, a similar pattern has emerged from limited studies in patients with diabetes. Short-term ARI treatment detectably improves nerve conduction in diabetic humans, thereby im-

1. Abbreviations used in this paper: ARI, aldose reductase inhibitor; BB-rat, Bio-Breeding rat; $\mathrm{MI}$, myo-inositol; $\mathrm{MNCV}$, motor nerve conduction velocity; PZI, protamine zinc insulin. 
plying a metabolically reversible component of the nerve conduction defect $(22,23)$, and prolonged ARI treatment partially reverses the biochemical defects and structural lesions associated with chronic symptomatic diabetic polyneuropathy (24). In two recent 1-yr clinical trials, ARI-treated patients demonstrated significant improvements in nerve sorbitol content $(24,25)$, whereas one of these studies failed to demonstrate any change in nerve MI content (25). In the larger study, the lowering of nerve sorbitol content was associated with a fourfold increase of nerve fiber regeneration, and a 33\% increase in myelinated fiber density (24) as well as improvements in axoglial dysjunction and axonal atrophy indicative of nerve fiber repair $(26,27)$. These biochemical and structural improvements were associated with small but significant improvements in electrophysiological and clinical indexes (24) that were consistent with the hypothesis that activation of the polyol pathway plays a continuous as well as initiating role in nerve fiber damage. Extrapolated over longer treatment periods these findings suggest that ARIs may reverse the structural abnormalities underlying clinically overt neuropathy and possibly ameliorate clinical symptoms and neurologic deficits. The possibility that ARI treatment, if initiated early in the course of diabetes, may substantially retard nerve fiber loss and atrophy and hence the development of overt diabetic neuropathy, was tested in the present animal experiment. Hyperglycemic BB-rats were treated with the ARI ponalrestat (Statil, ICI-Americas Inc., Wilmington, DE; Prodiax, Merck \& Co., Rahway, NJ) soon after the onset of diabetes and compared with untreated diabetic BB-rats. ARI treatment begun after 3 wk of hyperglycemia completely prevented the characteristic nerve conduction slowing, axoglial dysjunction, and axonal atrophy for $4 \mathrm{mo}$, whereas after $6 \mathrm{mo}$, prevention was only partial. Thus early initiation of ARI treatment at a dose that prevents early biochemical and functional defects significantly ameliorates but does not completely prevent the later occurring functional and structural aspects of diabetic neuropathy in the hyperglycemic BB-rat.

\section{Methods}

Animal model and experimental design. 20 prediabetic male BB-rats and 20 age-matched nondiabetes-prone male BB-rats were obtained from the National Institutes of Health colony at the Department of Pathology, University of Massachusetts, Worchester, MA. They were maintained in air-filtered metabolic cages with ad lib. access to water and rat chow (Wayne Lab Blox F-6, Wayne Laboratory Animal Diets, Wayne Feed Division, Winnipeg, MB) (MI content $0.022 \% \mathrm{wt} / \mathrm{wt}$ ). Body weight, urine volume, and glucosuria (Test Tape, Eli Lilly Canada Inc., Toronto, $\mathrm{ON}$ ) were monitored daily, and blood glucose was measured weekly in tail-vein blood samples by Ames Eyetone (Miles Laboratory Ltd., Rexdale, ON). Glycated hemoglobin (Gly Hb) was measured in tail-vein blood samples every second month and expressed as percent GlyHb using an affinity chromatography test kit (Glyco-Test, Pierce Chemical Co., Rockford, IL). After detection of glucosuria, diabetic rats were started on small daily doses (0.5-3.0 $\mathrm{U} \cdot \mathrm{d}^{-1}$ ) of protamine zinc insulin (PZI) (Connaught-Novo Inc. Toronto, $\mathrm{ON}$ ), designed to maintain blood glucose levels between 15 and $25 \mathrm{mmol} / \mathrm{liter} .3 \mathrm{wk}$ after the onset of diabetes, animals were randomly divided into two experimental groups: $(a)$ insulin-deficient untreated diabetic rats were continued on small doses of PZI designed to maintain hyperglycemia; $(b)$ ponalrestat-treated diabetic rats were similarly maintained on PZI, and fed a ponalrestat-supplemented rat laboratory diet $(80 \mathrm{~g}$ ponalrestat [ICI-Americas Inc., Wilmington, DE] per $100 \mathrm{~kg}$ of rat chow), equivalent to a daily dose of no less than $25 \mathrm{mg}$ of ponalrestat $/ \mathrm{kg}$ body wt. Age- and sex-matched nondiabetic control BB-rats were divided into two groups: $(a)$ untreated control rats, and (b) ponalrestat-treated control rats given the same ponalrestat-supplemented diet as described above (actual dosage: diabetic rats $32.6 \mathrm{mg} / \mathrm{kg}$ body wt; control rats $27.1 \mathrm{mg} / \mathrm{kg}$ body wt). Half the number of animals in each experimental group were killed at 4 mo of diabetes $(n=5$ per

Table I. Effect of ARI Treatment on Growth, Hyperglycemia, and Nerve Conduction

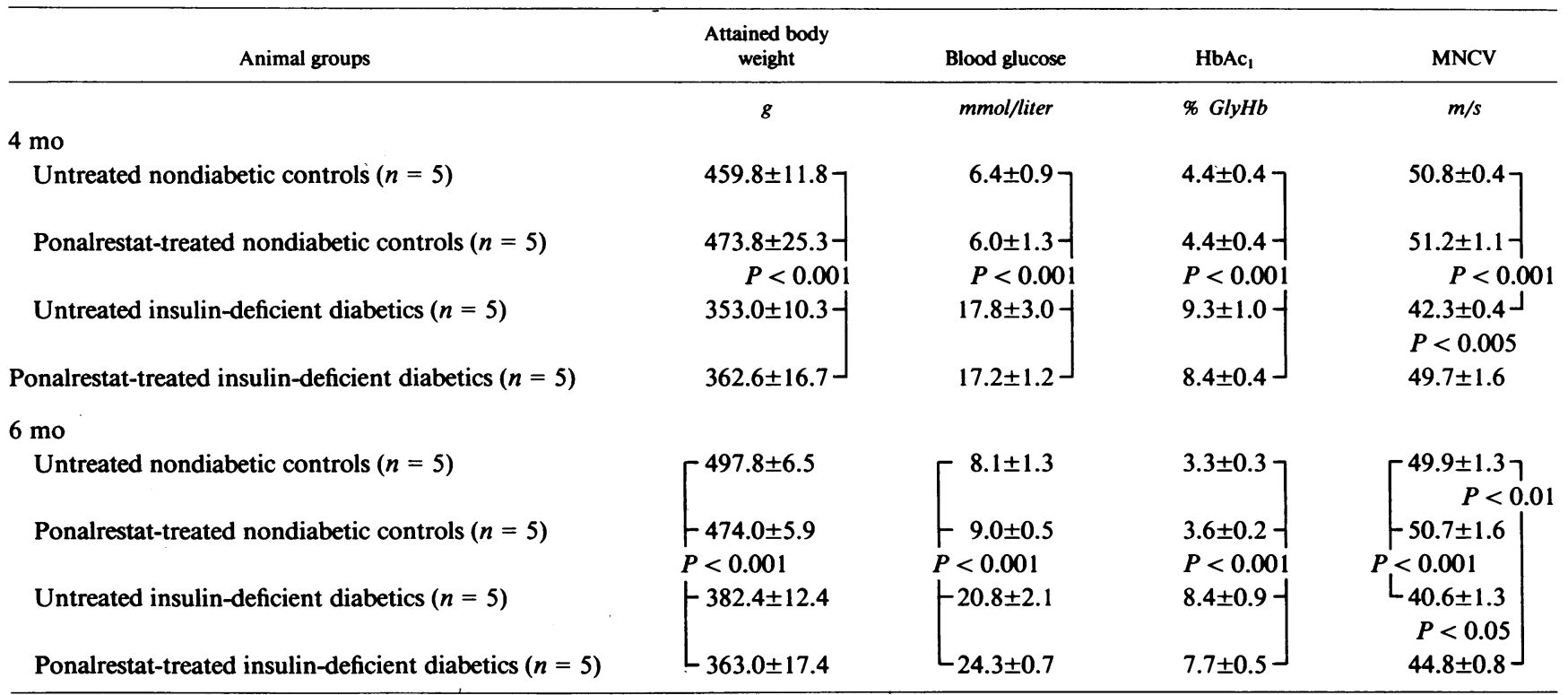

Data were obtained on the last day of the study protocols, after 4 and 6 mo of ponalrestat-treatment of insulin-deficient diabetes. ARI treatment had no effect on the characteristic loss in body weight gain in diabetic rats. Blood glucose and glycated hemoglobin levels were significantly elevated in untreated as well as ARI-treated diabetic rats. MNCVs were measured noninvasively in the sciatic-posterior tibial nerve conducting system. 4 mo of ponalrestat-treatment prevented completely the characteristic nerve conduction slowing in diabetic animals, whereas 6 mo of the same treatment resulted in a significant $(P<0.05)$, but only partial treatment effect. 


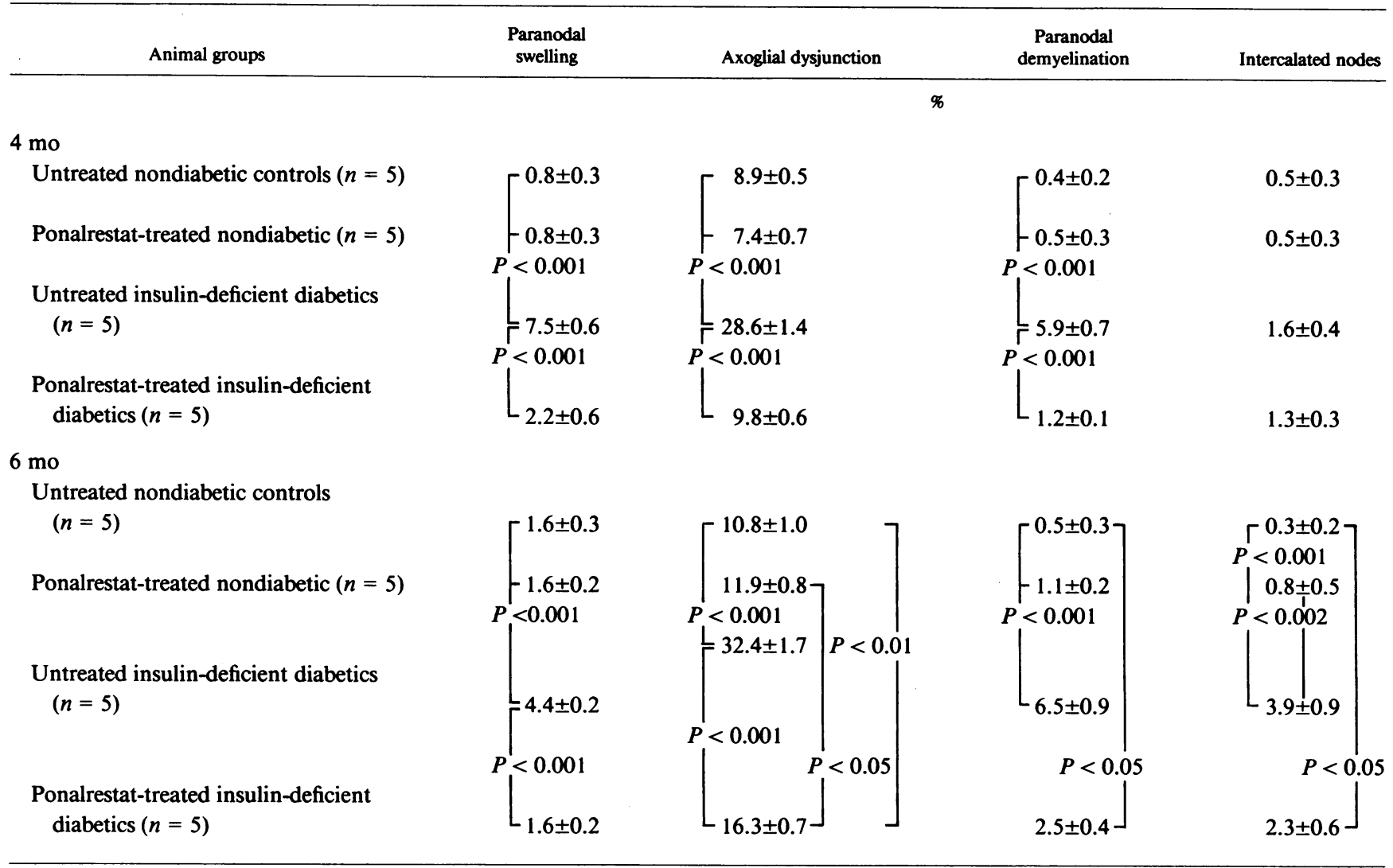

4 mo of ponalrestat-treated insulin-deficient diabetes resulted in a complete prevention of the sequential nodal abnormalities. After 6 mo of ARI-treatment a sustained complete prevention of paranodal swelling was demonstrated, whereas axoglial dysjunction and paranodal demyelination were only partially prevented and no significant treatment effect could be obtained with respect to intercalated nodes.

group) and half at 6 mo postdetection ( $n=5$ per group). End-point measurements, such as electrophysiological parameters and morphologic and morphometric assessments, were performed by investigators unaware of the identity of the animals.

Electrophysiological studies. Animals were lightly anesthetized with diethyl ether (Fisher Scientific Co., Fair Lawn, NJ). Motor nerve conduction velocity (MNCV) was determined noninvasively in the sciatic-posterior tibial conducting system in a temperature-controlled environment as previously described in detail (28). MNCV was calculated by subtracting the distal from the proximal latency measured in milliseconds and the difference was divided into the distance between the two stimulating electrodes measured in millimeters, yielding $\mathrm{MNCV}$ in meters per second.

Tissue collection. Nonfasted animals were anesthetized with $\mathrm{Na}$ pentobarbitol $(50 \mathrm{mg} / \mathrm{kg}$ body $\mathrm{wt})$. The sural nerve of the right side (opposite to the side on which MNCV was performed) was fixed in situ for $10 \mathrm{~min}$ by a cacodylate buffered (pH 7.40) $2.5 \%$ (vol/vol) glutaraldehyde fixative adjusted to an osmolality of 500 mosmol with sucrose for hyperglycemic animals to achieve serum isosmolality. The sural nerve was then carefully dissected, left in the same fixative for $4 \mathrm{~h}$ at $4^{\circ} \mathrm{C}$, and postfixed in cacodylate-buffered $1 \%$ osmium tetroxide ( $\mathrm{pH}$ 7.40) for $2 \mathrm{~h}$. The distal portion of the nerve was dehydrated in an ascending series of ethanol and embedded in Epon. Ultrathin cross and longitudinal sections were stained with aqueous uranyl acetate and lead citrate for electronmicroscopic examination. The proximal portion was used for teasing random single myelinated fibers in unpolymerized Epon.

Structural examinations. In order to quantify the neuroanatomical abnormalities, light- and electron-microscopic techniques were applied for the examination of longitudinal and cross sections of the sural nerve. Furthermore, pathologic scoring of single teased fibers was used to supplement the light- and electron-microscopic quantitative techniques as previously described $(21,29)$. Hence three independent techniques were used for morphometric analysis of the characteristic structural abnormalities of diabetic neuropathy.

Abnormalities of the node of Ranvier were assessed by scoring of teased fibers with respect to paranodal swelling, defined as a paranodal diameter $>150 \%$ of the internodal diameter, paranodal demyelination, and intercalated (remyelinated) nodes. These abnormalities were assessed from $95 \pm 3$ teased fibers per nerve and expressed as a percentage of the total number of teased fibers as previously described (29). The frequency of axoglial dysjunction was examined electronmicroscopically from a mean of $298 \pm 27$ terminal myelin loops per nerve. Serial longitudinal sections were examined for the absence of axoglial junctions between terminal myelin loops and the axolemmal membrane $(20,21)$. The frequency of myelin loops devoid of axoglial junctions was expressed as a percentage of the total myelin loops examined.

Axonal atrophy was assessed by scoring of teased fibers exhibiting excessive myelin wrinkling (thinnest internodal diameter $<50 \%$ of the thickest diameter) and expressed as a percentage of examined fibers. The severity of axonal atrophy was examined independently by calculating the axon/myelin ratio from a mean of $52 \pm 2$ myelinated fibers systematic randomly chosen from each sural nerve. Electronmicrographs of cross-sectioned sural nerves with a total magnification of 27,420 times were used to calculate the relationship between the natural logarithm of the axonal cross-sectional area and the myelin sheath thickness expressed by the number of myelin lamellae, by linear regression analysis. This relationship is increased during axonal swelling and decreased during axonal shrinkage (13).

Axonal degeneration was examined electronmicroscopically from 


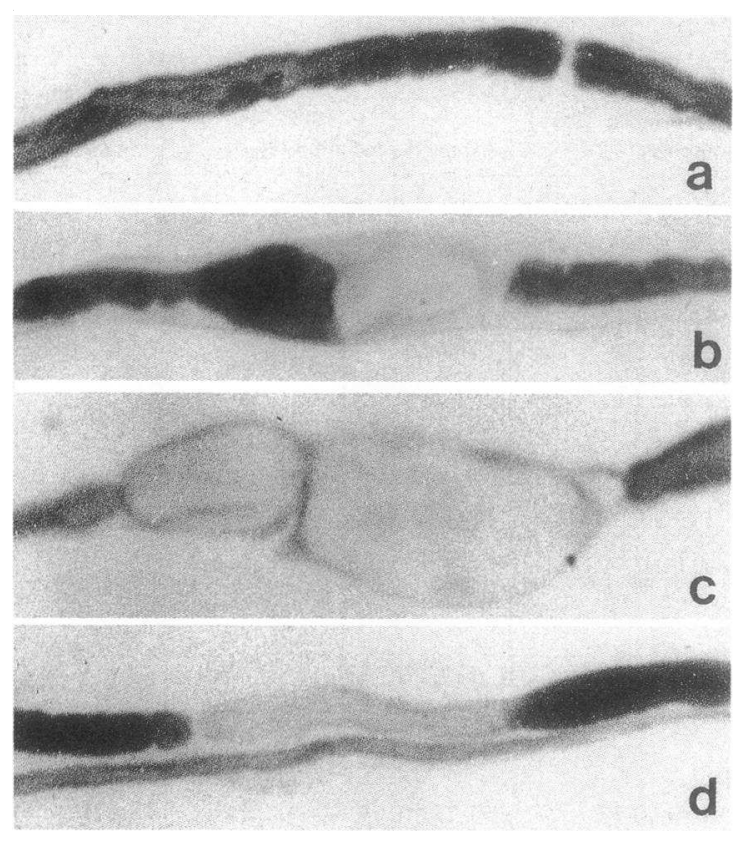

Figure 1. $(a-d)$ In diabetic neuropathy the nodal apparatus of myelinated nerve fibers undergoes a sequence of structural changes which can be readily identified and quantified in teased fiber preparations. (a) A myelinated nerve fiber with a structurally normal node of Ranvier. The earliest detectable change consists of paranodal swelling of the axon shown in $b$. Prolonged hyperglycemia leads to axoglial dysjunction (not shown) and paranodal myelin retraction, illustrated in $c$ together with sustained paranodal swelling. The demyelinated paranodal area subsequently undergoes remyelination with the formation of short, thinly myelinated intercalated nodes, illustrated in $d . \times 710$.

cross-sectioned sural nerves. Early axonal degeneration characterized by the ingrowth of Schwann cell lips into the axoplasm, so-called honeycombed profiles, and established axonal degeneration identified by granular and electron dense axoplasm were calculated as percentages of $\mathbf{4 0 0}$ systematic randomly chosen cross-sectioned myelinated fibers per nerve. Late axonal degeneration, Wallerian degeneration (segmentation into myelin ovoids and balls over several internodes), was assessed from teased fiber preparations and expressed as a percentage of total fibers examined (29).

Myelinated fiber size, fiber density, and fiber occupancy were calculated from semithin $(0.5 \mu \mathrm{m})$ toluidine blue-stained cross sections of the entire unifascicular sural nerve. Photographic prints with a magnification of 1,000 were used to calculate the area of each myelinated fiber with a HP 9872A digitizer interfaced with a HP 9825A desk computer and plotter (Hewlett-Packard Co., Cupertino, CA). The fascicular area was digitized from photographic prints with a total magnification of 250 . Myelinated fiber density per unit area and myelinated fiber occupancy (percentage of the fascicular area occupied by myelinated fibers) were calculated $(13,29)$.

Myelinated fiber regeneration identified by redundant basement membranes was quantified from cross-sectional electron micrographs of $\mathbf{4 0 0}$ systematic randomly selected myelinated fibers. The frequency of regenerating fibers characterized by short internodes, were also assessed by scoring of teased fiber preparations (internodes $<50 \%$ of normal for fiber diameter) (29).

Normal myelinated fibers were assessed electron-microscopically and expressed as a percentage of 400 examined cross-sectioned fibers in each nerve or by scoring of teased fibers and expressed as a percentage. Primary myelin degeneration characterized by segmental demyelination was quantified from teased fiber preparations.

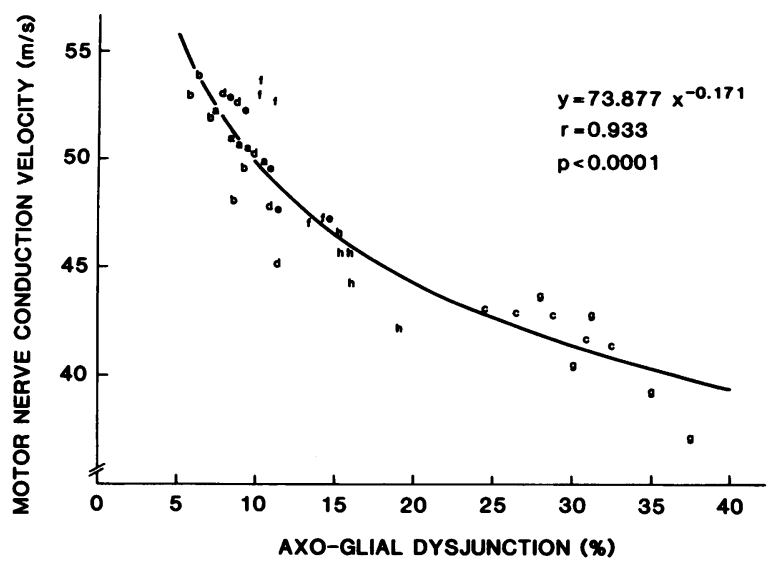

Figure 2. Correlation between MNCV and axoglial dysjunction in 4-mo untreated nondiabetic controls $(a)$, ponalrestat-treated nondiabetic controls $(b)$, untreated insulin-deficient diabetics $(c)$, ponalrestat-treated insulin-deficient diabetics $(d)$, and 6-mo nondiabetic controls $(e)$, ponalrestat-treated controls $(f)$, insulin-deficient diabetics $(g)$, and ponalrestat-treated insulin-deficient diabetics $(h)$. MNCV and axoglial dysjunction showed a highly significant $(P<0.0001)$ inverse correlation, suggesting that axoglial dysjunction is a major determinant for nerve conduction slowing in both ponalrestat-treated and untreated insulin-deficient BB-rats.

Statistics. The results are presented as mean \pm SEM, and the significance of differences was calculated by analysis of variance (ANOVA), and modified $t$ test. Multiple linear regression analysis was performed by the method of least squares.

\section{Results}

\section{Clinical responses to ARI treatment (Table I)}

After 4 mo of insulin-deficient diabetes, BB-rats with or without ponalrestat treatment showed reduced body weight in excess of $20 \%$ compared with nondiabetic controls, and elevated blood glucose and glycated hemoglobin values (Table I, columns 1, 2, and 3, upper panel). Untreated diabetic BB-rats showed a $17 \%$ reduction $(P<0.001)$ in tibial MNCV, whereas no reduction in MNCV could be demonstrated in ponalrestattreated diabetic BB-rats (Table I, column 4, upper panel). ARI treatment of control rats had no influence on body weight, blood glucose, glycated hemoglobin, or MNCV.

At the termination of the experimental protocol, ARItreated and untreated diabetic rats continued to show $a>20 \%$ reduction in body weight and significant elevations in blood glucose and glycated hemoglobin levels (Table I, columns 1, 2, and 3, lower panel). Untreated diabetic rats showed a $19 \%$ reduction in MNCV compared with controls, whereas ponalrestat-treated diabetic rats showed an intermediate MNCV, $10 \%$ less than in controls but $10 \%$ greater than in untreated diabetic BB-rats (Table I, column 4, lower panel). 6 mo of Ponalrestat treatment of control rats had no effect on body weight, blood glucose, glycated hemoglobin, or MNCV (Table I).

\section{Structural findings}

Abnormalities of the node of Ranvier (Table II; Figs. 1 and 2). The diabetic BB-rat and humans exhibit a sequence of pathological changes involving the nodal apparatus of myelinated fibers, initiated by paranodal axonal swelling, followed by axoglial dysjunction, paranodal demyelination, and interca- 


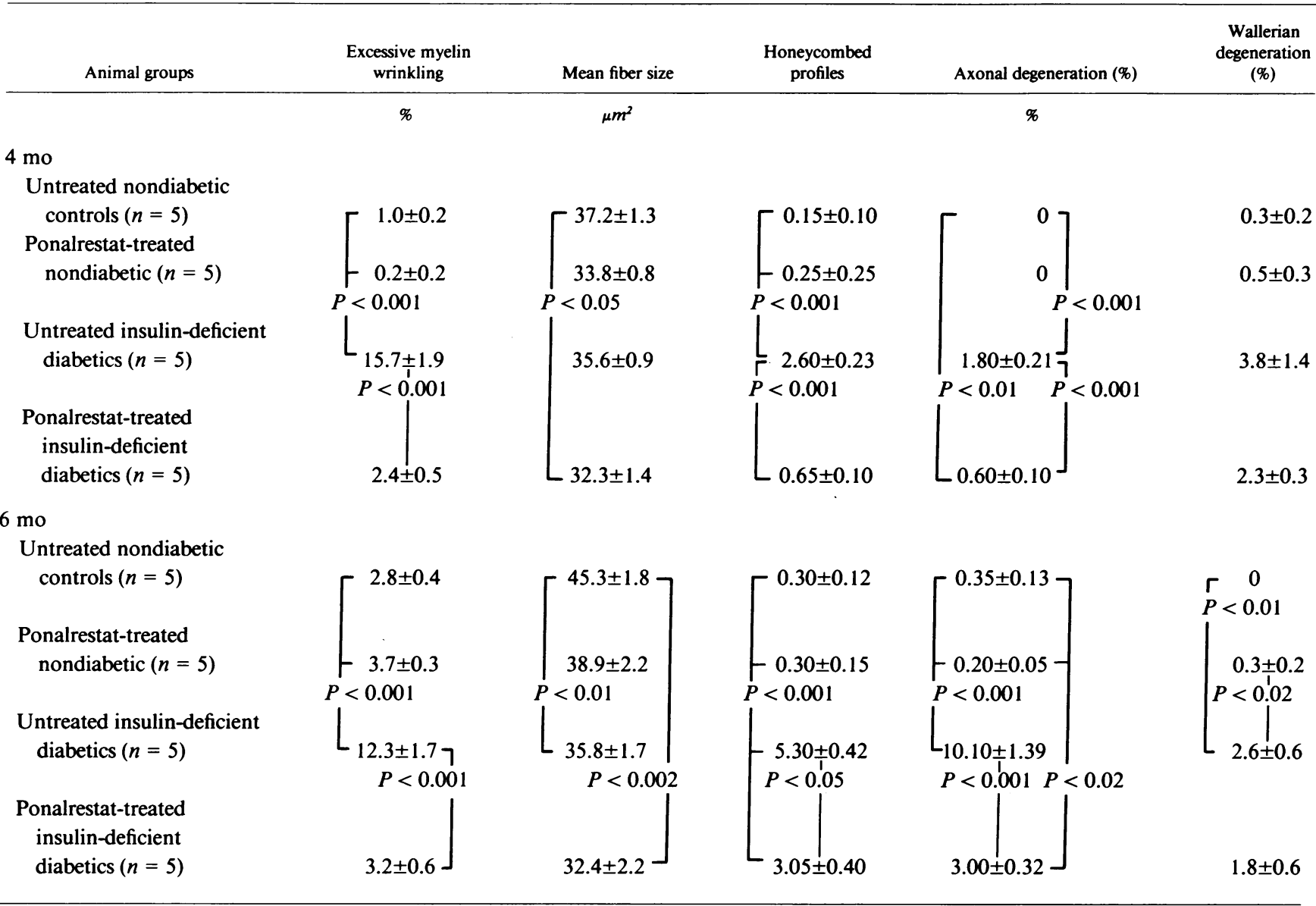

Axonal atrophy was assessed by the frequency of fibers exhibiting excessive myelin wrinkling. It was prominent in untreated insulin-deficient diabetic BB-rats both at 4 and 6 mo of diabetes, and was fully prevented by ponalrestat treatment. Insulin-deficient diabetic rats treated with ARI consistently showed decreased mean myelinated fiber size. 4 mo of ponalrestat-treatment prevented early axonal degeneration (honeycombed profiles) fully, and axonal degeneration partially, whereas 6 mo of treatment achieved only partial but significant preventive effects on honeycombed profiles and established axonal degeneration. No significant treatment effect could be established when Wallerian degeneration was assessed.

lated remyelinated nodes (Fig. 1) $(21,29)$. In the present study untreated rats showed significant increases in the frequencies of early nodal abnormalities such as paranodal swelling, axoglial dysjunction, and paranodal demyelination whereas advanced nodal pathology, reflected by intercalated nodes, was absent at 4 mo of diabetes (Table II, columns 1-4, upper panel). After 6 mo of untreated diabetes a significant increase in the frequency of intercalated nodes was detected (Table II, column 4, lower panel). 4 mo of Ponalrestat treatment of diabetic rats completely prevented early nodal abnormalities such as paranodal swelling, axoglial dysjunction, and paranodal demyelination (Table II, columns 1-3, upper panel). Ponalrestat

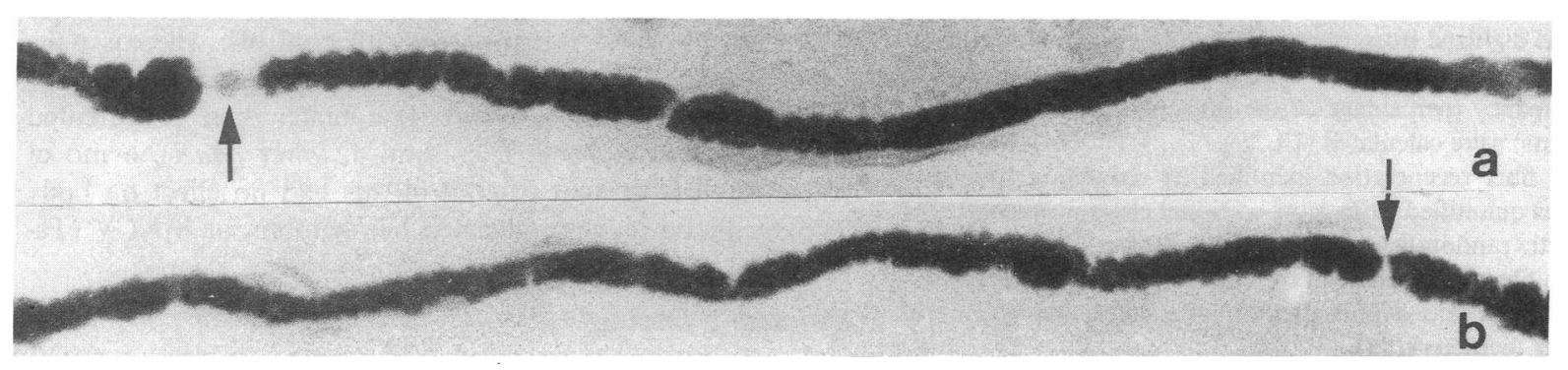

Figure 3. Axonal atrophy is one of the most common structural lesions in diabetic neuropathy and is identified in single teased fiber preparations as an excessive wrinkling of the myelin sheath which becomes redundant around the shrunken axon. $(a$ and $b$ ) Sequential photographs of a myelinated fiber showing excessive myelin wrinkling. The nodes of Ranvier are indicated by arrows. $\times 710$. 


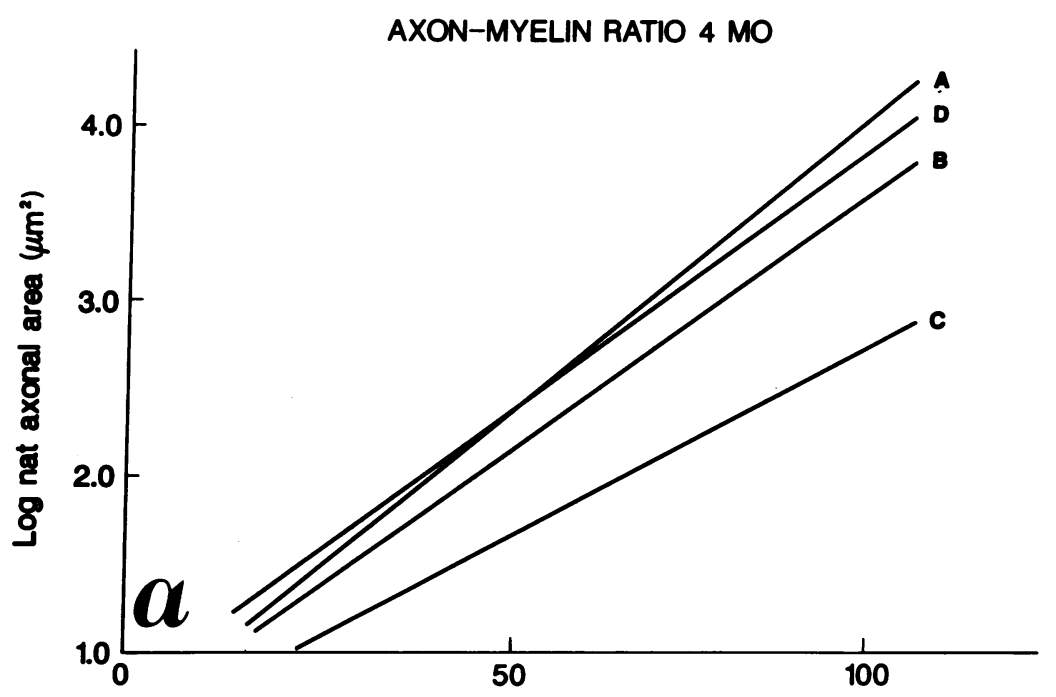

Number of myelin lamellae

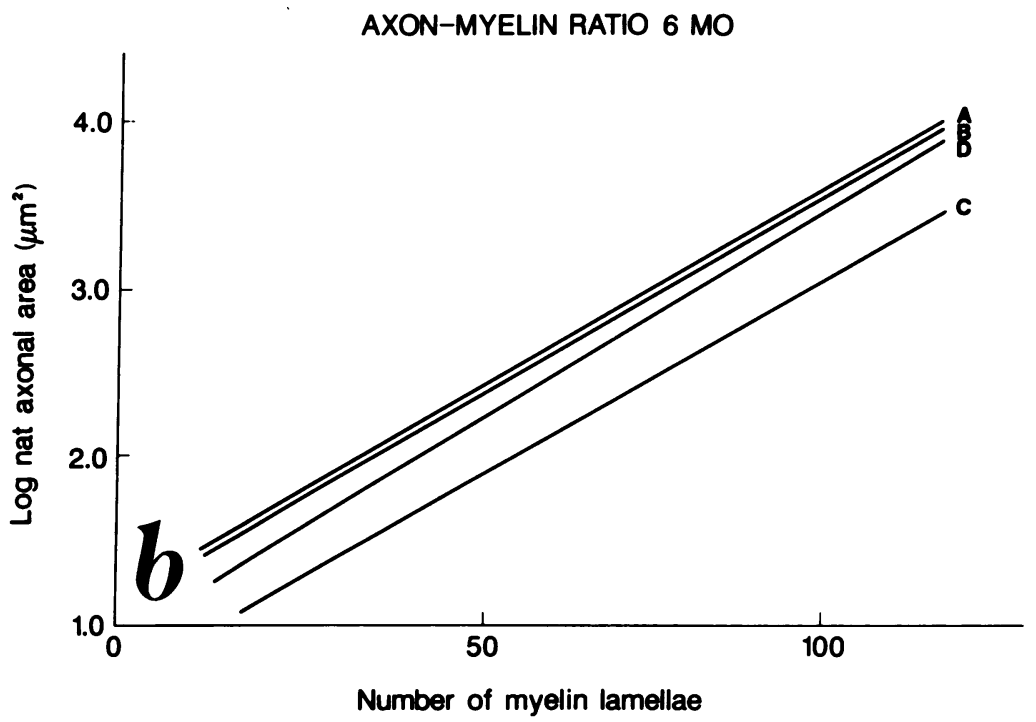

A: Untreated Non-diabetic controls, $n=5$

$a=0.571 \pm 0.112$

$b=0.035 \pm 0.002$
$r^{2}=0.753 \pm 0.052$

B; Ponalrestat-treated Non-diabetic controts, $n=5$

$a=0.597 \pm 0.106$

$b=0.030 \pm 0.002$

C; Untreated Insulin-Deficient Diabetics, $n=5$

$a=0.496 \pm 0.070$

$b=0.022 \pm 0.002$
$r^{2}=0.536 \pm 0.054$

D; Ponalrestat-treated Insulin-Deficient Diabetics, $n=5$ $a=0.763 \pm 0.169$ $b=0.031 \pm 0.002$

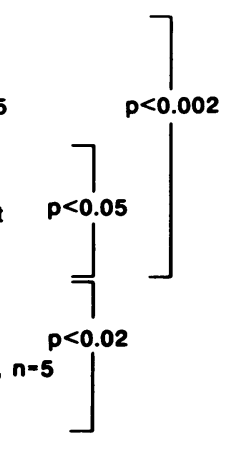

A: Untreated Non-diabetic controls, $n=5$

$a=1.258 \pm 0.141$ $b=0.023 \pm 0.002$
$r^{2}=0.585 \pm 0.059$

B; Ponalrestat-treated Non-diabetic controls, $n=5$ $a=1.221 \pm 0.115$ $\mathrm{b}=0.023 \pm 0.003$

c: Untreated Insulin-Deficient Diabetics, $n=5$

$a=0.651 \pm 0.063$ $b=0.024 \pm 0.002$
$r^{2}=0.684 \pm 0.032$

D; Ponalrestat-treated Insulin-Deficient Diabetics, $n=5$ $a=0.946 \pm 0.071$ $b=0.025 \pm 0.001$
$r^{2}=0.480+0.059$

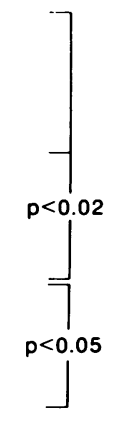

Figure 4. The severity of axonal atrophy can be assessed by the decrease in the normally linear relationship between the natural logarithm of the axonal area regressed over the myelin sheath thickness expressed by the number of myelin lamellae. (a) The axon/myelin regressions are illustrated for 4-mo treated and untreated nondiabetic, and insulin-deficient diabetic BB-rats. (b) The same assessments of the axon/myelin ratios after 6 mo of treatment. A decrease in the regression coefficient or the intercept signifies axonal atrophy.

treatment completely prevented paranodal axonal swelling, and significantly reduced but did not entirely prevent more advanced nodal changes such as axoglial dysjunction, paranodal demyelination, and intercalated nodes at 6 mos (Table II, columns $1-4$, lower panel).

MNCV and the frequency of axoglial dysjunction showed a negative exponential correlation in ponalrestat-treated and untreated nondiabetic and diabetic BB-rats $(n=40 ; r=0.933$; $P<0.0001$ for the equation $y=a \cdot x^{b}$; Fig. 2). Also, when tested for a linear relationship, a highly significant correlation was obtained $(n=40 ; r=0.912 ; P<0.0001$ for the equation $y$ $=a+b x$; the slope being $-0.45 \mathrm{~m} / \mathrm{s}$ per percent axoglial dysjunction), suggesting that nerve conduction slowing is closely related to the loss of axoglial junctions.
Axonal atrophy, myelinated fiber size, density, and occupancy (Table III; Figs. 3 and 4). Axonal atrophy is characterized by excessive wrinkling of the myelin sheath in teased fiber preparations (Fig. 3) and a decrease in the axon/myelin ratio in electron microscopic sections (21) (Fig. 4). The frequency of excessively wrinkled myelinated fibers was markedly $(P$ $<0.001$ ) increased (Table III, column 1) and the axon/myelin ratio decreased (Fig. 4 ) in untreated diabetic rats, both at 4 and 6 mo compared with their respective age-matched controls. ARI treatment completely prevented excessive myelin wrinkling and the decrease in axon/myelin ratio in diabetic BB-rats at 4 and 6 mo (Table III; Fig. 4 b). Ponalrestat treatment had no effect on excessive myelin wrinkling in control rats (Table III, column 1). 

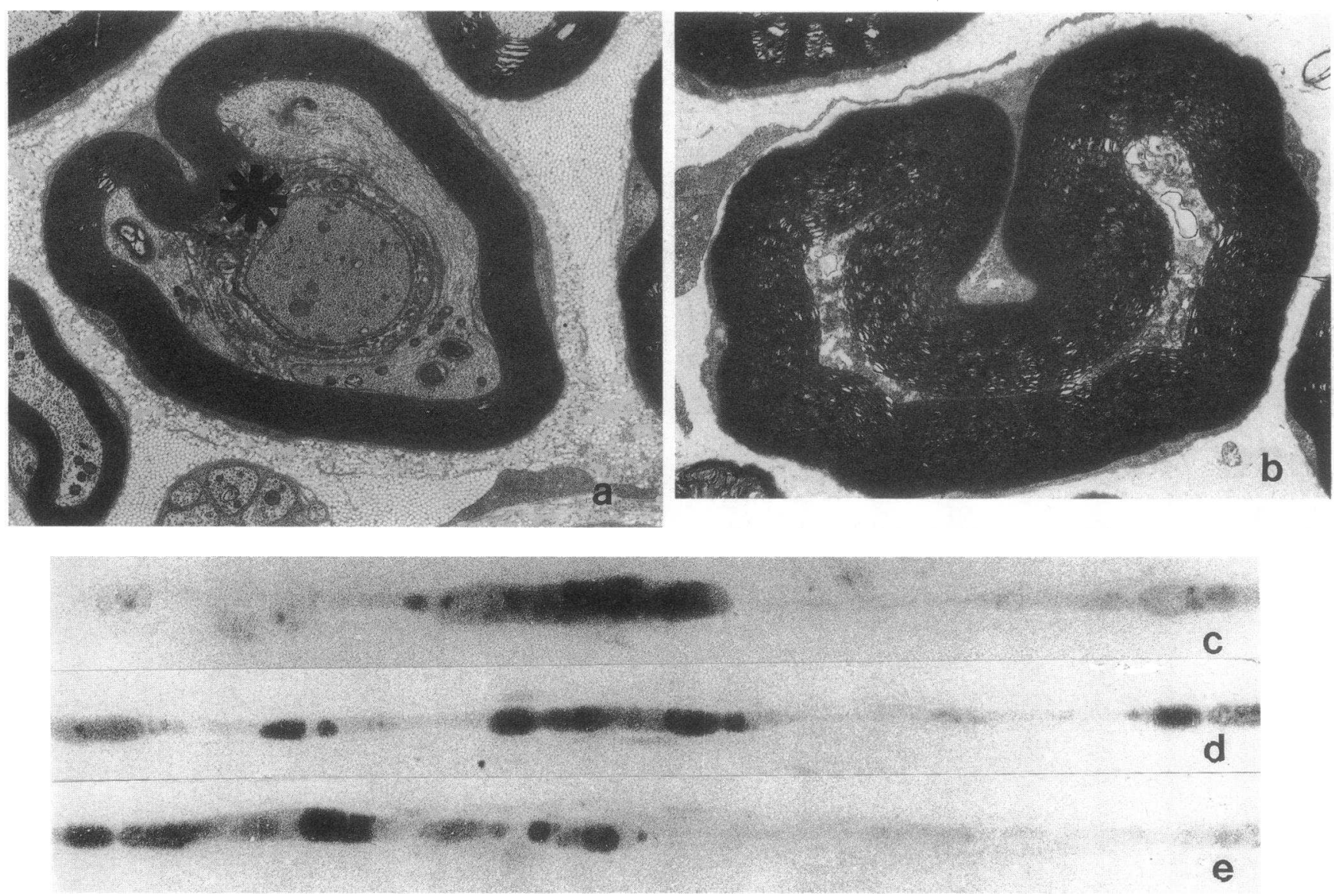

Figure 5. (a-e) Axonal degeneration is a characteristic structural abnormality in diabetic neuropathy. Frank axonal degeneration is preceded by sequestration of abnormal axoplasm by the ingrowth of the inner Schwann cell lip $(*)$, a structural change referred to as honeycombed profiles (a). $\times 6,670$ times. In frank axonal degeneration the cytoskeletal structures show loss in detail and the axoplasm attains a granular appearance, although the structural details of the myelin sheath may be retained as illustrated in $b \times 7,300$. The ultimate fate of the degenerating axon is the complete disintegration of the whole myelinated fiber with secondary breakup of the myelin sheath, so-called Wallerian degeneration, which is illustrated by sequential photographs of the same fiber in $c-e . \times 710$.

At $4 \mathrm{mo}$, neither untreated diabetes nor ponalrestat treatment in nondiabetic rats affected mean fiber size, but there was a marginal but statistically significant decrease in mean fiber size in the ponalrestat-treated diabetic rats (Table III, column 2, upper panel). At 6 mo, mean fiber size was reduced in untreated diabetic rats, and ponalrestat treatment affected mean fiber size in neither normal nor diabetic rats (Table III, column 2, lower panel). Ponalrestat treatment in 6 mo diabetic rats was associated with a statistically insignificant decrease in fiber occupancy $(43.8 \pm 2.2 \%$ vs. $49.4 \pm 2.9 \%$ in untreated diabetic rats, $P=\mathrm{ns}$ ), and fiber density was statistically insignificantly lower in the untreated controls compared to the other three experimental groups at $6 \mathrm{mo}\left(11,559 \pm 947 \mathrm{fibers} / \mathrm{mm}^{2}\right.$ vs. $13,578 \pm 685,13,793 \pm 383$, and $13,671 \pm 700$ fibers $/ \mathrm{mm}^{2}$ in the ponalrestat-treated controls, untreated, and ponalrestattreated diabetic rats, respectively, all $P=\mathrm{ns}$ ).

Axonal degeneration (Table III; Fig. 5). The process of axonal degeneration, which proceeds through a series of subtle ultrastructurally identifiable stages before ultimately leading to loss of myelinated fibers, characterizes diabetic neuropathy. Honeycombed axonal profiles ("axonal sequestration") (Fig. 5 a), which in other axonopathies are thought to herald axonal degeneration $(30,31)$, were 17 -fold more common in 4- and 6-mo diabetic rats compared with control rats. ARI treatment completely prevented the development of this alteration for 4 mo and reduced its occurrence by $45 \%$ at 6 mo (Table III, column 3). Frank axonal degeneration characterized ultrastructurally by granulated and electrodense axoplasm (Fig. $5 \mathrm{~b}$ ) was markedly increased in 4- and 6-mo diabetic rats (Table III, column 4) and was reduced by 60 and $70 \%$, respectively, by ponalrestat treatment. Wallerian degeneration was significantly increased after 6 mo of untreated diabetes (Fig. 5, $c-e$ ) and was slightly but statistically insignificantly reduced in the Ponalrestat-treated diabetics compared to untreated diabetics (Table III, column 5, lower panel).

Myelinated fiber regeneration (Table IV; Fig. 6) as assessed by scoring of teased myelinated fibers (Fig. $6 a$ ), and by ultrastructural examination (Fig. $6 b$ ) was significantly increased in untreated 4- and 6-mo diabetic rats when compared with agematched untreated control rats. (Table IV, columns 1 and 2). ARI treatment of 4- and 6-mo diabetic BB-rats increased by threefold the frequencies of regenerating myelinated fibers. 


\begin{tabular}{|c|c|c|c|c|}
\hline \multirow[b]{2}{*}{ Animal groups } & \multicolumn{2}{|c|}{ Myelinated fiber regeneration } & \multicolumn{2}{|c|}{ Normal myelinated fibers } \\
\hline & $\begin{array}{l}\text { Teased fiber } \\
\text { evaluation }\end{array}$ & $\begin{array}{l}\text { Ultrastructural } \\
\text { evaluation }\end{array}$ & $\begin{array}{l}\text { Teased fibers } \\
\text { evaluation }\end{array}$ & $\begin{array}{l}\text { Ultrastructurally } \\
\text { evaluation }\end{array}$ \\
\hline & & 9 & & \\
\hline \multicolumn{5}{|l|}{$4 \mathrm{mo}$} \\
\hline Untreated nondiabetic controls $(n=5)$ & {$\left[\begin{array}{c}1.8 \pm 0.4 \\
P<0.001\end{array}\right]$} & {$[0$} & {$[95.9 \pm 0.6]$} & $98.8 \pm 0.27$ \\
\hline Ponalrestat-treated nondiabetic $(n=5)$ & $\underset{P<0.05}{5.2 \pm 0.4}$ & $\begin{array}{l}0 \\
P<0.05\end{array}$ & $\begin{array}{c}\mid 91.4 \pm 0.8 \\
P<0.001\end{array}$ & $\begin{aligned} 97.9 & \pm 0.3- \\
P & <0.001\end{aligned}$ \\
\hline Untreated insulin-deficient diabetics $(n=5)$ & $\begin{array}{r}L 3.7 \pm 0.2 \\
P<0.001\end{array}$ & $\underset{P<0.001}{1.20 \pm 0.27\rfloor}$ & $\begin{array}{r}L_{61.9 \pm 3.5 \mid} \mid \\
\mid P<0.00\end{array}$ & $\begin{array}{r}84.5 \pm 1.2 \dashv \\
P<0.001\end{array}$ \\
\hline Ponalrestat-treated insulin-deficient diabetics $(n=5)$ & $\begin{array}{r}\mid P<0 . C \\
12.1 \pm 1.4\end{array}$ & $L_{6.55 \pm 0.76}$ & $\left.\begin{array}{l}P<0.01 \\
78.4 \pm 1.7\end{array}\right]$ & $90.9 \pm 0.9$ \\
\hline \multicolumn{5}{|l|}{$6 \mathrm{mo}$} \\
\hline Untreated nondiabetic controls $(n=5)$ & {$\left[\begin{array}{c}1.3 \pm 0.47 \\
P<0.05 \\
P<0.001\end{array}\right.$} & $\Gamma$ & {$\left[\begin{array}{l}92.8 \pm 0.7 \\
P<0.05\end{array}\right.$} & $96.6 \pm 0.37$ \\
\hline Ponalrestat-treated nondiabetic $(n=5)$ & $-4.8 \pm 0.2$ & $\begin{array}{c}\mid 0.70 \pm 0.09- \\
P<0.05\end{array} \mid$ & $\begin{array}{l}-86.5 \pm 0.4 \\
P<0.001\end{array}$ & $\begin{aligned} & 96.0 \pm 0.2- \\
& P<0.001\end{aligned}$ \\
\hline Untreated insulin-deficient diabetics $(n=5)$ & $P_{P<0.001}^{-5.2 \pm 1.7}$ & $\begin{aligned} \mathrm{L}_{2.40} & \pm 0.23- \\
P & <0.001\end{aligned}$ & $\begin{aligned} &-65.1 \pm 1.97 \\
& P<0.02\end{aligned}$ & $77.1 \pm 1.9 \dashv$ \\
\hline Ponalrestat-treated insulin-deficient diabetics $(n=5)$ & $L_{15.5 \pm 2.3}$ & $18.2 \pm 1.73\rfloor$ & {$[75.6 \pm 3.0]$} & $78.2 \pm 1.2\rfloor$ \\
\hline
\end{tabular}

Regenerating myelinated fibers were identified in teased fiber preparation by their short internodes (compare Fig. $6 a$ ). Ultrastructurally regenerating myelinated fibers were assessed as a percentage of examined fibers. They were identified by redundant basement membranes (compare Fig. 6 b). ARI treatment resulted in a multifold increase in regenerating fibers both in insulin-deficient diabetic rats and in nondiabetic control rats. The decrease in the frequency of normal myelinated fibers, whether assessed by teased single fibers or ultrastructurally, was only partially prevented by ARI treatment at 4 and 6 mo. The residual abnormalities after ARI treatment were almost exclusively due to "abnormal" regenerating fibers.

Ponalrestat also increased the frequency of regenerating myelinated fibers in nondiabetic control rats (Table IV, column 1).

Normal myelinated fibers and primary demyelination (Table IV). The percentage of teased nerve fibers with a normal appearance was markedly decreased in 4- and 6-mo diabetic rats compared to age-matched controls. This decrease was significantly but not completely prevented by ARI-treatment in 4- and 6-mo diabetic rats (Table IV, column 3). The quantification of normal fibers based on electron-microscopic cross sections, which overlooks nodal abnormalities and is a poor discriminator of axonal atrophy, produced similar results (Table 4, column 4).

Segmental demyelination which is not a prominent morphologic feature of diabetic neuropathy $(7,29)$ was unaltered by either diabetes or ARI treatment at 4 or 6 mo (data not shown).

\section{Discussion}

In the present study, aldose reductase inhibition with the experimental ARI, ponalrestat, at a dose previously shown to normalize nerve conduction, MI content, (Na,K)-ATPase activity, and nodal architecture in acute diabetes $(8,32)$, completely prevented the characteristic nerve conduction slowing and the development of the sequential nodal abnormalities in diabetic BB-rats, for up to 4 mo, despite persistent hyperglycemia and the characteristic lack of body wt gain. Axonal atrophy as assessed by the axon/myelin ratio, and the presence of excessive myelin wrinkling was also prevented by ponalrestat treatment for up to $4 \mathrm{mo}$. These findings are thus in agreement with prevention of the reported defect in slow antegrade axonal transport of structural proteins in diabetic rats after aldose reductase inhibition $(9,10,33-35)$. In contrast, subtle axonal degenerative changes were only partially prevented by 4-mo ARI treatment, suggesting that they may reflect processes other than polyol-pathway activation or may be more sensitive to this metabolic defect if aldose reductase was only partially inhibited. The residual axonal degeneration could possibly reflect nonenzymatic glycation of axonal structural proteins interfering with their normal polymerization and assembly (36). The preservation of normal nerve conduction in the presence of residual axonal sequestration suggests that this structural parameter is a poor indicator of nerve dysfunction. In contrast, the close correlation between nerve conduction slowing and the loss of axoglial junctions, indicates that axoglial dysjunction is an important structural determinant for the nerve conduction (21). Hence, ARI treatment appears to prevent the major functional and functionally relevant structural abnormalities developing after 4 mo of diabetes in the BB-rat. These findings implicate activation of the polyol pathway by hyperglycemia as a major factor in the development of 


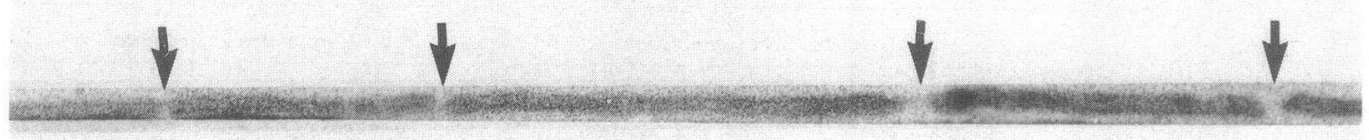

a

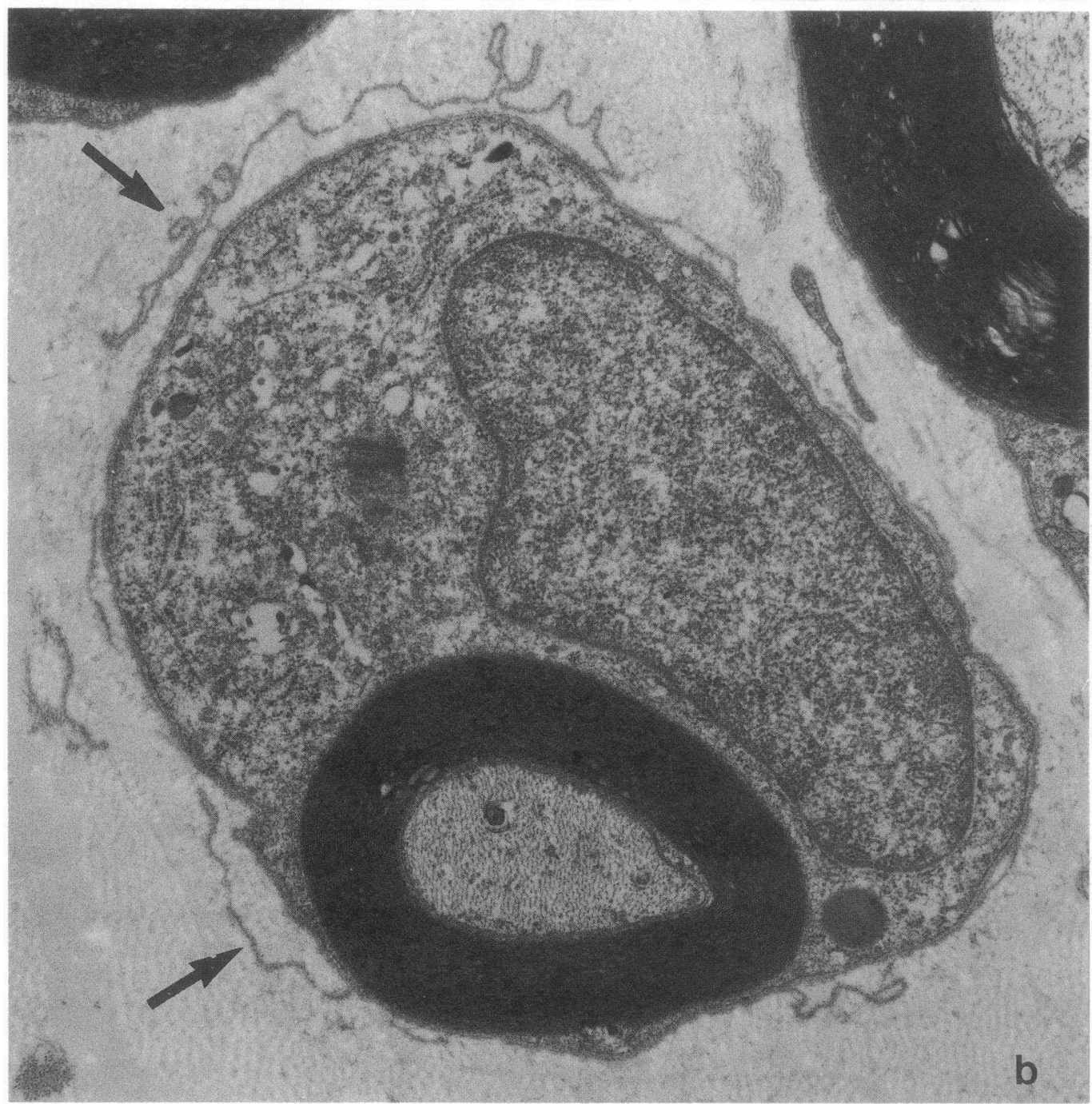

Figure 6. Ponalrestat treatment resulted in an increase in the frequencies of regenerated myelinated fibers. In teased fiber preparations regenerated fibers are characterized by thinly myelinated fibers with short internodes (indicated by arrows) illustrated in $a$. $\times 710$. Ultrastructurally, regenerating myelinated fibers are readily recognized by a redundant basement membrane (arrows), which is retained from the previously degenerated fiber that they replace illustrated in $b . \times 17,500$.

important structural abnormalities thought to underlie diabetic neuropathy. These results are in disagreement with those obtained by Bhoyrul et al. (37) after 3 mo of Ponalrestat-treatment in streptozotocin diabetic rats. These authors reported an exacerbation of axonal degeneration after combined ARI and insulin treatment despite the fact that nerve sorbitol levels were normalized and nerve. MI levels partially corrected. Although these authors ascribed this exacerbation to ponalrestat, it is more likely that the exacerbated nerve fiber degeneration was a consequence of episodes of insulin-induced hypoglycemia (38).
Ponalrestat treatment was able to partially prevent the development of nerve conduction slowing and nodal structural defects after 6 mo of diabetes in the BB-rat. The 10\% faster nerve conduction in ponalrestat-treated vs. untreated diabetic rats was accompanied by significant but partial prevention of axonal degeneration and axoglial dysjunction, whereas axonal atrophy was fully prevented in hyperglycemic BB-rats for the full 6-mo study period. The lack of complete prevention of axoglial dysjunction after 6 mo of Ponalrestat treatment is most likely responsible for the slowing of nerve conduction since the nerve conduction slowing correlated closely with 
axoglial dysjunction but not with axonal atrophy. The fact that paranodal swelling was completely, but axoglial dysjunction only partially prevented by Ponalrestat, suggests that axoglial dysjunction may not be a sequela of paranodal swelling as we have previously suggested (21), or that axoglial dysjunction is a more sensitive indicator of residual aldose reductase activity at some site in peripheral nerve than is paranodal swelling. For example, it is possible that the MI-related protein kinase $\mathrm{C}$ dysmetabolism in diabetic nerve may independently affect axoglial junctions via dynamic regulation of specific Schwann cell adhesion molecules, so called cell junctional molecules (39) independent of its putative effect on axonal ( Na,K)-ATPase. Therefore, after this prolonged period of hyperglycemic exposure of peripheral nerve, the continuous inhibition of the polyol pathway begun $3 \mathrm{wk}$ after the onset of diabetes is either incomplete or insufficient to fully prevent axoglial dysjunction and degenerative axonal changes.

Apart from the significant effect of ARI treatment on normally occurring functional and structural abnormalities in peripheral nerve of the diabetic BB-rat, ponalrestat-treated rats showed a threefold increase in the frequency of regenerating fibers. Since regenerated fibers are of small size, their addition to the preexisting fiber complement probably accounts for the decreased mean fiber size in ponalrestat-treated diabetic rats. These findings are similar to those previously described after 12 mo of aldose reductase inhibition in human diabetic neuropathy (24) and would suggest that the metabolic abnormalities in diabetic nerve not only contribute to nerve degeneration but may also blunt the normal regenerative capacity after nerve injury. It is possible that the same defect in the MI-related protein kinase $C$ signaling mechanism that is suggested to explain the $(\mathrm{Na}, \mathrm{K})$-ATPase defect in peripheral nerve may have an inhibitory effect on the responsiveness to neurotrophic factors necessary for nerve regeneration. Alternatively, the syntheses of neurotrophic factors such as nerve growth factor may be directly affected by the diabetic dysmetabolism, resulting in a defect in the neurotrophic "tone" necessary to sustain the structural and functional integrity of peripheral nerve. Such constructs would explain the burst of myelinated fiber regeneration after aldose reductase inhibition in both human and murin diabetic neuropathy. The threefold increase in the frequency of regenerating fibers after ponalrestat treatment of control rats would suggest that, besides a possible defect of neurotrophism in the diabetic state, ponalrestat in itself may have a primary or secondary promoting effect on neurotrophism by some unexplained mechanism.

In summary, 6 mo of ponalrestat treatment in the diabetic BB-rat has a significant protective effect on the development of the characteristic nerve conduction slowing and structural peripheral nerve lesions. Furthermore, the same treatment appears to markedly promote nerve fiber regeneration in the diabetic nerve by an as yet unknown mechanism. From the present data we conclude that ARIs may prove to be useful adjuvants to the therapeutic arsenal in preventing diabetic neuropathy.

\section{Acknowledgment}

The authors are indebted to Mrs. Jackie McKane for preparing the manuscript.
This study was supported by grants from ICI Pharmaceuticals Division, Macclesfield, UK (ICI-RDN3), the Medical Research Council of Canada (MT-10673, MA-10674), and the U. S. Public Health Service (DK-38304). Dr. Zhang is supported by a fellowship from ICIAmerica, Wilmington, DE, and Dr. Chakrabarti is supported by a postdoctoral fellowship from Diabetes Canada.

\section{References}

1. Greene, D. A., S. A. Lattimer, J. Ulbrecht, and P. Carrol. 1985. Glucose-induced alterations in nerve metabolism: current perspective on the pathogenesis of diabetic neuropathy and future directions for research and therapy. Diabetes Care. 8:290-299.

2. Greene, D. A., S. A. Lattimer, and A. A. F. Sima. 1988. Perspectives in Diabetes: Are disturbances of sorbitol, phosphoinositide and $(\mathrm{Na}, \mathrm{K})$-ATP-ase regulation involved in the pathogenesis of diabetic neuropathy? Diabetes. 37:688-693.

3. Winegrad, A. I., D. A. Simmons, and D. B. Martin. 1983. Has one diabetic complication been explained? N. Engl. J. Med. 308:152154.

4. Winegrad, A. I. 1987. Does a common mechanism induce the diverse complications of diabetes? Diabetes. 36:396-406.

5. Greene, D. A., P. V. deJesus, Jr., and A. I. Winegrad. 1975. Effect of insulin and dietary myo-inositol on impaired peripheral motor nerve conduction velocity in acute streptozotocin diabetes. $J$. Clin. Invest. 55:1326-1336.

6. Robertson, D. M., and A. A. F. Sima. 1980. Diabetic neuropathy in the mutant mouse [C57BL/Ks $(\mathrm{db} / \mathrm{db})]$ : a morphometric study. Diabetes. 29:60-67.

7. Sima, A. A. F. 1985. Annotation: can the BB-rat help to unravel diabetic neuropathy? Neuropathol. Appl. Neurobiol. 11:253-264.

8. Greene, D. A., C. Chakrabarti, S. A. Lattimer, and A. A. F. Sima. 1987. Role of sorbitol accumulation and myo-inositol depletion in paranodal swelling of large myelinated nerve fibers in the insulin-deficient spontaneously diabetic bio-breeding rat: reversal by insulin replacement, an aldose reductase inhibitor, and myo-inositol. J. Clin. Invest. 79:1479-1485.

9. Tomlinson, D. R., P. R. Holmes, and J. H. Mayer. 1982. Reversal by treatment with an aldose reductase inhibitor of impaired axonal transport and motor nerve conduction velocity in experimental diabetes. Neurosci. Lett. 31:189-193.

10. Tomlinson, D. R., R. J. Moriarty, and J. H. Mayer. 1984. Prevention and reversal of defective axonal transport and motor nerve conduction velocity in rats with experimental diabetes, by treatment with the aldose reductase inhibitor Sorbinil. Diabetes. 33:470-476.

11. Ward, J. D., C. G. Bowes, D. J. Fisher, J. D. Jessop, and W. R. Boher. 1971. Improvement in nerve conduction following treatment in newly diagnosed diabetics. Lancet. $i: 428-430$.

12. Terkidsen, A. B., and N. J. Christensen. 1971. Reversible nervous abnormalities in juvenile diabetics with recently diagnosed diabetes. Diabetologia. 7:113-117.

13. Sima, A. A. F., M. Bouchier, and H. Christensen. 1983. Axonal atrophy in sensory nerves of the diabetic BB-Wistar rat: a possible early correlate of human diabetic neuropathy. Ann. Neurol. 13:264-272.

14. Sima, A. A. F. 1984. Neuropathic and occular complications in the BB-Wistar rat. In Lessons from Animal Diabetes. E. Shafrir and A. E. Renold, editors. John Libbey, London. 449-456.

15. Greene, D. A., S. Yagihashi, S. A. Lattimer, and A. A. F. Sima. 1984. Nerve $\mathrm{Na}^{+}-\mathrm{K}^{+}$-ATP-ase, conduction and myo-inositol in the insulin deficient BB-rat. Am. J. Physiol. 247:E534-E539.

16. Lattimer, S. A., A. A. F. Sima, and D. A. Greene. 1989. In vitro correction of impaired $\mathrm{Na}^{+}-\mathrm{K}^{+}$-ATP-ase in diabetic nerve by protein kinase C-agonists. Am. J. Physiol. 256:E264-E269.

17. Lee, T. S., L. C. MacGregor, S. J. Fluharty, G. L. King. 1989. Differential regulation of protein kinase $\mathrm{C}$ and $(\mathrm{Na}, \mathrm{K})$-adenosine tri- 
phosphate activities by elevated glucose levels in retinal capillary endothelial cells. J. Clin. Invest. 83:90-94.

18. Brismar, T., and A. A. F. Sima. 1981. Changes in nodal function in nerve fibers of the spontaneously diabetic BB-Wistar rat: potential clamp analysis. Acta Physiol. Scand. 113:499-506.

19. Sima, A. A. F., and T. Brismar. 1985. Reversible diabetic nerve dysfunction: structural correlates to electrophysiological abnormalities. Ann. Neurol. 18:21-29.

20. Brismar, T., A. A. F. Sima, and D. A. Greene. 1987. Reversible and irreversible nodal dysfunction in diabetic neuropathy. Ann. Neurol. 21:504-507.

21. Sima, A. A. F., S. A. Lattimer, S. Yagihashi, and D. A. Greene. 1986. Axo-glial dysjunction: a novel structural lesion that accounts for poorly reversible slowing of nerve conduction in the spontaneously diabetic BB-rat. J. Clin. Invest. 77:474-484.

22. Judzewitsch, R. G., J. B. Jaspan, K. S. Polonsky, C. R. Weinberg, J. B. Halter, E. Halar, M. A. Pfeiffer, G. Vakadinovic, L. Bernstein, M. Schneider, et al. 1983. Aldose reductase inhibition improves nerve conduction velocity in diabetic patients. N. Engl. J. Med. 308:119-125.

23. Fagius, J., A. Brattberg, S. Jameson, and C. Berne. 1985. Limited benefit of treatment of diabetic polyneuropathy with an aldose reductase inhibitor: a 24-week controlled trial. Diabetologia. 28:323329.

24. Sima, A. A. F., V. Bril, V. Nathaniel, T. A. J. McEwen, M. B. Brown, S. A. Lattimer, and D. A. Greene. 1988. Regeneration and repair of myelinated fibers in sural-nerve biopsy specimens from patients with diabetic neuropathy treated with sorbinil. $N$. Engl. J. Med. 319:548-555

25. Dyck, P. J., B. R. Zimmerman, T. H. Vilen, S. R. Minnerath, J. I. Karnes, J. K. Yao, J. F. Podulso. 1988. Nerve glucose, fructose, sorbitol, myo-inositol, and fiber degeneration and regeneration in diabetic neuropathy. N. Engl. J. Med. 319:542-548.

26. Sima, A. A. F., V. Nathaniel, V. Bril, S. A. Lattimer, and D. A. Greene. 1988. The effect of sorbinil treatment on diabetic neuropathy. In Polyol Pathway and its Role in Diabetic Complications. N. Sakamoto, J. H. Kinoshita, P. F. Kador, and N. Hotta, editors. Elsevier Science Publishers BV, Amsterdam. 416-421.

27. Sima, A. A. F. The effect of aldose reductase inhibition on human diabetic neuropathy. In Proceedings of the 2nd World Conference on Diabetes Research, JDFI, Monaco, 1988.

28. Sima, A. A. F., and K. Hay. 1981. Functional aspects and pathogenetic considerations of the neuropathy in the spontaneously diabetic BB-Wistar rat. Neuropathol. Appl. Neurobiol. 7:341-350.

29. Sima, A. A. F., V. Nathaniel, V. Bril, T. A. J. McEwen, and D. A. Greene. 1988. Histopathological heterogeneity of neuropathy in insulin-dependent and non-insulin-dependent diabetes, and demonstration of axoglial dysjunction in human diabetic neuropathy. J. Clin. Invest. 81:349-364.

30. Spencer, P. S., and H. H. Schaumburg. 1976. Central peripheral distal axonopathy - the pathology of dying-back polyneuropathies. Prog. Neuropathol. 3:253-295.

31. Asbury, A. K., and M. J. Brown. 1980. The evolution of structural changes in distal axonopathies. In Experimental and Clinical Neurotoxicology. P. S. Spencer and H. H. Schaumburg, editors. Williams \& Wilkins Co., Baltimore. 179-192.

32. Greene, D. A., S. A. Lattimer, and A. A. F. Sima. 1987. Sorbitol, phosphoinositides and the sodium-potassium ATP-ase in the pathogenesis of diabetic complications. N. Engl. J. Med. 316:599-606.

33. Tomlinson, D. R., J. Townsend, and P. Fulten. 1985. Prevention of defective axonal transport in streptozotocin-diabetic rats by treatment with "Statil" (ICI-128436) an aldose reductase inhibitor Diabetes. 34:970-972.

34. Medori, R., L. Autilio-Gambetti, H. Jenich, and P. Gambetti. 1988. Changes in axonal size and slow axonal transport are related in experimental diabetic neuropathy. Neurology. 38:597-601.

35. Medori, R., H. Jenich, L. Autilio-Gambetti, and P. Gambetti. 1988. Experimental diabetic neuropathy: similar changes of slow axonal transport and axonal size in different animal models. J. Neurosci. 8:1814-1821.

36. Williams, S. K., N. L. Howarth, J. J. Devenny, and M. W. Bilensky. 1982. Structural and functional consequences of increased tubulin glycosylation in diabetes mellitus. Proc. Natl. Acad. Sci. USA 79:6546-6550.

37. Bhoyrul, S., A. K. Sharma, D. Stribling, D. D. Mirrlees, R. G. Peterson, M. O. Farber, and P. K. Thomas. 1988. Ultrastructural observations on myelinated fibres in experimental diabetes: effect of the aldose reductase inhibitor ponalrestat given alone or in conjunction with insulin therapy. J. Neurol. Sci. 85:131-147.

38. Sima, A. A. F., W.-X. Zhang, and D. A. Greene. 1989. Diabetic and hypoglycemic neuropathy: a comparison in the BB-rat. Diabetes Res. Clin. Pract. 6:279-296.

39. Edelman, G. M. 1987. CAMs and Igs: cell adhesion and the evolutionary origins of immunity. Immunol. Rev. 100:11-45. 